\title{
Reproductive and demographic Predictors' of premenstrual syndrome severity among university students
}

\author{
Fatma Ali Oraby1,Magda Ahmed Fawaz 2\& Nadia Bassuoni El-Sharkawy3 \\ 1 Clinical instructor ofBenha Children's Hospital Specialist, Egypt. \\ 2 Assist.Prof of Maternal and Newborn Health Nursing, Faculty of Nursing, Cairo University, Egypt. \\ 3 Lecturer of Maternal and Newborn Health Nursing, Faculty of Nursing, Cairo University, Egypt
}

\begin{abstract}
Background: Premenstrual syndrome (PMS)is a group of psychological and somatic symptoms related to menstrual cycle amongyoung and middle-aged women. These symptoms occur during the luteal phase of the menstrual cycle.

Aim of the study: Toexplore reproductive and demographic predictors that might affect premenstrual syndrome severity among University Students

Design: a cross sectional descriptive research design was utilized for the current study.

Setting: The study was conducted at Banha University.

Sample: A purposive sample of 250students were included

Three tools were used to collect data; (1) Self-administered structured questionnaire sheet, (2) visual analogue scale, and (3) premenstrual symptomatology tool.

Results: The study findings reveal that type of collage, mother's levels of education, family history of PMS, menstrual cycle intervals were the important predictors that might affect severity of $P M S(P=<0.05,0.02$, $<0.05 \& 0.043$ respectively. Also, the results indicated that, menstrual irregularities, BMI and duration of menstrual flow were not statistically significant in relation to severity of $P M S(P=0.14,0.45 \& 0.08$ respectively).

Conclusion: The problem of premenstrual syndrome is prevalent among University students and measures to raise awareness to reduce this problem are important and beneficial.
\end{abstract}

Keywords: premenstrual syndrome, predictors, reproductive; Socio-demographic, university students.

\section{Introduction}

Premenstrual syndrome (PMS) is the name given to a collection of physical and psychological symptoms that some women experience during the late luteal phase of each menstrual cycle ( 7 to 14 days prior to menstruation). Symptoms seem to worsen as menstruation approaches and subside at the onset or after several days of menstruation $(1,2)$. The exact causes of PMS are not clearly understood but have been attributed to hormonal changes, neurotransmitters, prostaglandins, diet, drugs, and lifestyle (3, 4). PMS reported in the literature falls into three domains: emotional, physical, and behavioral. The most common emotional and moodrelated symptoms of PMS include depression, irritability, and tension, crying, over sensitivity (hypersensitivity), and mood swings (5).

Premenstrual syndrome (PMS) is a significant health issue for women with a reported prevalence of $47.8 \%$ ( 6).Premenstrual syndrome can negatively impact a women's life for up to six days monthly. Common symptoms of PMS include, but are not limited to: depression, mood labiality, abdominal pain, breast tenderness, headache and fatigue (7) .PMS is associated with increased sick days, impaired work productivity, impaired marital relationships and homemaking difficulties, and impaired functioning; reduced quality of life has been reported in collegiate women suffering from PMS with decreased educational productivity, disruptions in social activities, and impairments in family relations (8).

There are certain factors that might affects severity of premenstrual syndrome symptomatology such as stress $(9,10)$, practicing exercise(10), sleep quality(11), caffeine intake(10) and body mass index $(\mathrm{BMI})(10,12)$. In addition, credit load, work environment, living situation and marital status are likely to contribute to PMS. On the contrary, the risk factors which can contribute to severity of PMS include were family history; increased physical and mental stress; low BMI; young age at menarche; longer duration of menstrual flow; sweet foods and increasing age after menarche were independent predictors of PMS (13).However, these factors remain inconsistency, further researches is necessary to exploring the influence of various factors on PMS severity. So, understanding the influence of various factors on PMS severity is highly important for the development of intervention strategies for women suffering from PMS. The nurse has a crucial role in the prevention and management of premenstrual syndrome, the nurse should perform careful assessment for the presence of risk factors as age, menstrual problems, stress, and life style habits. Also, education is another important role that the 
nurse should teach the associated symptoms with menstrual cycle, time of appearance of symptoms as well as aggregating factors. Moreover, the nurse can alleviate some of the anxiety associated with premenstrual syndrome by offering explanation about timing and reasons for each symptom. In addition, the nurse should be familiarwith menstrual problem, pattern of coping, and gynecological centers for referral

\section{Significance of the study}

Premenstrual syndrome is among the commonest gynecological problems among young women; also incorrect beliefs regarding menstrual complaints do not warrant the attention of health care providers that lead the young women suffer in salient. The findings of this study were add to the body of nursing knowledge about associated factors that affects the severity of PMS among university students to improve quality of life among these target population. Also, this study might serve as a foundation for future public health and women health research in this neglected area. Moreover, the findings of this study might also help in the development of appropriate policies, plans and intervention programs for the management and treatment of PMS in women health centers.

\section{Operational definition}

Predictors: In the current research refers to factorsthat might affect severity of PMS among University students as measured by interviewing questionnaire schedule.

\section{Aim of the study}

The aim of the current study wastoexplore reproductive and demographic predictors that might affect premenstrual syndrome severity.

Research Question: To fulfill the aims of the current study the following research question are formulated What are the reproductive and demographic predictors that might affect severity of PMS among university students?

\section{Research design}

\section{Subjects and Methods}

A descriptive Cross Sectional research design was chosen to answer the research question. Setting

The current study was conducted among student's residence at Banha University indoors during the academic year. This setting consists of five floors each floor contains ten rooms the setting provides services in the form of providing housing security, clean and healthy diets. The university indoors provides these services for 500 students per year.

\section{Sample}

A purposive sample of 250 university student were chosen based on the following sample size calculation using the equation considering the percentage of PMS, confidence level, and margin of error.

Description

$n=$ required sample size.

$t=$ confidence level at $95 \%$ (standard value of 1.96).

$p=$ estimated prevalence of PMS in the study area $(80 \%)$.

$m=$ margin of error at $5 \%$ (standard value of 0.05$)$.

$n=(1.96) 2 \times 0.8(1-0.8) /(0.05) 2$.

The recruited sample was chosen based on the following inclusion criteria: unmarried university female students aged between 18 and 25 years from different universities and levels. Students with any previous history of chronic illness as diabetes, high blood pressure and heart disease were excluded from the study

Tools for data collection:three tools were used to collect the data from the students and included the following; 1). Self-administered structured questionnaire tool: This tool includes two parts:- Part a) describe personal demographic data of the study sample such as: age, type of college, academic year, mother's level of education, body mass index and norms of sleep pattern per day; part b-) describe Reproductive profile of the study sample; such as age at menarche, menstrual regularity, menstrual cycle interval (days), duration of menstrual flow (days), number of pads changed per day and presence of dysmenorrhea .

2). Visual analogue scale: This tool used to measure severity of pain associated with menstruation ranged from 0-10 as (0) denote absent of pain, score below (3) for mild pain, score from 3 to 6 for moderate pain and score of 7 to 10 for severe pain.

3). Premenstrual symptomatology tool: This tool includes data regarding: premenstrual physical, psychological and behavioral symptoms for two successive cycles by using Likert scale ranged from (0-3). Score (0) denote 
absent of symptoms; score (1) mild, score (2) moderate (as interfere with daily activities); and score(3) denotes severe symptoms as intolerable., The total scores were calculated and divided into three categories: - A score from 0- 21 denote mild symptoms, score from 22- 42 denote moderate premenstrual symptomatology and severe premenstrual symptomatology ranging from 43 to 63 scores.

\section{Validity and reliability of the tools}

Tools of the study was given to 5 experts in the field of maternity nursing and obstetric medicine to test the content validity of the tool and clarifies the sentences as well as,appropriateness of content. After the questionnaire was collected, test- retest reliability was applied by the researcher for testing the internal consistency of the tool. It was done through the administration of the same tools to the same participants under similar conditions on two or more occasions. Scores from repeated testing were compared.

\section{Pilot study}

A pilot study was conducted on $10 \%$ of the sample to assess the feasibility and clarity of the tools and determine the needed time to complete the tools. Based on the results of the pilot study some modifications were carried out on the tool so, subjects were included in the pilot study was excluded.

\section{Procedure}

The current study was carried out on two phases: preparatory phase and interviewing phases.

1-Preparatory phase: The research investigator contacted the administrative personnel responsible for the university campus to explain the purpose from the study, benefits to participants and then obtained a written approval to conduct the study. Also, during this phase the research investigator designs the tools.

2- Interviewing phase: Data was collected through a period of 3 months from Februaryto April 2016. During this phase, the research investigator collected the needed data from the study sample in two cycles by using self-administered structured questionnaire. Also, the research investigator meets the study sample recruited two days every week (Sunday and Tuesday) from $5 \mathrm{pm}-9 \mathrm{pm}$ based on their requests to collect the data for two cycles. The interview was taking place in the nursing room. The research investigator interviewed about 25 students at every visit. The research investigator introduced herself to the study sample and explained the purpose of the study and obtained their written consent to be participating in the study. All the study sample who fulfil the inclusion criteria, the research investigator explains how to fill out the questionnaire for two cycles before the onset of period 7 days as well as, the study sample were asked to rate their PMS symptoms using the premenstrual symptomatology tool throughout the two cycles. The interview consumed about 20 minutes for each student. Also, anthropometric assessment was carried out after obtaining the baseline data, that the research investigator measured the study sample height through tape measurement. and weight utilizing bath scale, accuracy wasobtained through balancing zero prior to obtainingeach weightand then body mass indexis calculatedby dividing the subject weight in kilograms by the square of her height in meters (BMI= $\mathrm{kg} /$ $\mathrm{m} 2$ ). Anthropometric assessment was consumed about 10 minutes for each one.

\section{Human rights and ethical considerations}

A primary approval was taken from the ethical Committee at the Faculty of Nursing- Cairo University to conduct the study. Also, each participant informed about the purpose of the study and its importance. The researcher emphasized that participation in the study is entirely voluntary; anonymity and confidentiality were assured through coding the data as well as, participants were informed of their right to withdraw from the study at any time. For those who accept to be participated in this study, informed written consent was obtained from each participant.

Statistical Analysis:The collected data were coded and tabulated using personal computer. Statistical package for social science (SPSS) version 20 was used. The researcher used the descriptive as well as inferential statistics. The descriptive statistics include thearithmetic Mean as an average, describing central tendency of observation of each variable studied; the standard deviation as a measure of dispersion of results around the mean; and the frequency distribution and percentage of observation for each variable studied were used. Statistical significance was considered at p-value $<0.05$.

\section{Results}

Findings of this cross sectional research design was presented in two main sections: 1) description of the study sample; 2) Reproductive and demographic predictors that might affect severity of PMS among University students.

I: Description of the study ample: This section includes three subsections: a) personal demographic data of the study sample; b) Menstrual profile; and c) Pre-Menstrual symptomatology for two successive menstrual cycles. a) Personal demographic data of the study sample: the age range of the study sample ranged from 18 to 26 years old with a mean of $20.5 \pm 0.97$ years old. Fifty-three point two percent of the study samples were students 
in practical colleges as compared to $46.8 \%$ of the study sample were students in theoretical colleges. Eighty-four point four percent of the study samples the number of family members ranged from 4-6 members. Thirty-nine point two percent of the study samples were at third level compared to $13.6 \%$ was at fourth level. Sixty three point six percent of the study sample was lived in ruralresidence. Moreover, $41.6 \%$ of study samples their mother's had completed diploma education compared to $2.4 \%$ of them their mothers had post graduate education. Regarding to body mass index categories, the results revealed that $55.2 \%$ of the sample had within normal weight as compared to $0.4 \%$ of the sample has moderate obesity (table, 1 ).

B) Menstrual profile of the study sample: the mean age of menarche was $13.15 \pm 1.148$ years old. More than two thirds $(67.2 \%)$ of the study sample had regular menstrual cycle and $52.8 \%$ of them had menstrual cycle interval /days ranged from 25-29 days as compared to $8.4 \%$ their had menstrual interval /days was more than 35 days. Regarding to duration of menstrual flow (days), the study findings reveals that $73.2 \%$ of study samples had a menstrual duration ranged from 2-6 days as compared to $8.4 \%$ ranged from 7-10 days respectively. Moreover, $78.8 \%$ of the study sample they changed 2 - 4 pads / day. Also, $48.4 \%$ reported that they suffer from severe menstrual pain. Nearly half (46\%) of the study sample had severe PMS. As perceived by the $54.8 \%$ from the study sample had a family history of PMS; as $47.4 \%$ of them their sisters had a history of PMS. More than three quarters $(89.6 \%)(\mathrm{n}=224)$ from the study sample the PMS effects their daily; negative impact of premenstrual syndrome on daily live; more than half (54.5\%) of the study sample had negative impact on out of the house with family (table, 2).

C)Pre-Menstrual symptomology:This section includes premenstrual symptomatology in two successive menstrual cycles among the study sample (physical, psychological, and behavioral symptoms. Regarding to physical symptoms, more than half from the study sample $(65.2 \%, 66.8 \%)$ had $\geq 7$ of physical symptoms compared to $(10.4 \%, 9.6 \%$ respectively) had $\leq 3$ of physical symptoms. Also, $62.4 \%, 62.8 \%$ from the study sample had $\geq 5$ of psychological symptoms compared to $(13.6 \%, 14 \%$ respectively)had $\leq 2$ from psychological symptoms. Moreover, nearly more than half of the study sample $(58 \%, 58.4 \%)$ had $\geq 4$ of behavioral symptoms compared to $(17.6 \%, 18.4 \%) \mathrm{had} \leq 2$ from behavioral symptoms (table, 3$)$.

Regarding to the types of premenstrual symptomatology throughout the two cycles, the results reveals that $(93.2 \%, 93.6 \%)$ from the study sample had reported tiredness and or/fatigue were the commonest severity of physical symptoms compared to (52\% and 56\% respectively) from the study sample had constipation (Figure,1). For premenstrual psychological symptoms severity, $87.2 \%$ and $88.8 \%$ from the study sample had reported mood changes compared to $61.6 \%$ and $63.2 \%$ suffer from crying (Figure, 2). In addition, Severity of Premenstrual behavioral symptoms was reported by $88.8 \%$ and $90 \%$ ) from the study sample in the form of lack of daily activity compared to $70.4 \%$ and $72.4 \%$ ) reported eating too much salty food during menstrual cycle (Figure, 3 )

\section{2- Reproductive and Demographic predictors that might affect severity of PMS}

1-Demographic Predictors: Results indicated that type of collage, the number of family member and mother's level of education, were the important predictors that might affect severity of PMS ( $\mathrm{P}=0.000,0.019,0028$ respectively) Also, the results indicated that age, academic year, residence and body mass index were not statistically significant $(\mathrm{P}=0.476,0.059,0.434,0.148$ respectively) (table, 4$)$.

2-Reproductive Predictors: Results indicated that menstrual cycle intervals, family history of PMS and dysmenorrhea, were the important predictors that might affect severity of PMS ( $\mathrm{P}=0.000 \& 0.000$ respectively). Also, the study findings indicated that menstrual regularities, number of pads changed / day and duration of menstrual flow were not statistically significant $(\mathrm{P}=0.081,0.397 \& 0.450$ respectively) (table, 5).

Table (1): Personal Socio-demographic Characteristics of the studied Sample $(\mathrm{n}=250)$

\begin{tabular}{|l|l|l|}
\hline -Demographic Characteristics & No & \% \\
\hline Age (year) & \multicolumn{2}{|l|}{} \\
\hline $18-20$ & 166 & 66.4 \\
\hline $21-23$ & 76 & 30.4 \\
\hline $24-26$ & 8 & 3.2 \\
\hline Mean + SD & $20.5 \pm 0.97$ & \\
\hline College Type & \multicolumn{2}{|l|}{} \\
\hline Theoretical & 117 & 46.8 \\
\hline Practical & 133 & 53.2 \\
\hline The number of family members & \multicolumn{2}{|l|}{} \\
\hline $4-6$ & 211 & 84.4 \\
\hline $7-9$ & 37 & 14.8 \\
\hline $10-11$ & 2 & 0.8 \\
\hline Academic year & \multicolumn{2}{|l|}{} \\
\hline First & 78 & 31.2 \\
\hline Second & 40 & 16 \\
\hline Third & 98 & 39.2 \\
\hline Fourth & 34 & 13.6 \\
\hline
\end{tabular}


Reproductive and demographic Predictors' of premenstrual syndrome severity among university

\begin{tabular}{|l|l|l|}
\hline Residence & & \\
\hline Rural & 159 & 63.6 \\
\hline Urban & 91 & 36.4 \\
\hline Mother's level of education & & \\
\hline Not read or write & 28 & 11.2 \\
\hline Read and write & 21 & 8.4 \\
\hline Primary & 7 & 2.8 \\
\hline Preparatory & 15 & 6 \\
\hline Secondary & 104 & 41.6 \\
\hline University & 69 & 27.6 \\
\hline Post graduate & 6 & 2.4 \\
\hline Body mass index & & \\
\hline Under weight $\left(16-18.5 \mathrm{Kg} / \mathrm{m}^{2}\right)$ & 4 & 1.6 \\
\hline Normal weight $\left(18.5\right.$ to $\left.25 \mathrm{Kg} / \mathrm{m}^{2}\right)$ & 138 & 55.2 \\
\hline Over weight $\left(25\right.$ to $\left.30 \mathrm{Kg} / \mathrm{m}^{2}\right)$ & 95 & 38 \\
\hline Mild obesity $\left(30\right.$ to $\left.35 \mathrm{Kg} / \mathrm{m}^{2}\right)$ & 12 & 4.8 \\
\hline Moderate obesity $\left(35\right.$ to $\left.40 \mathrm{Kg} / \mathrm{m}^{2}\right)$ & 1 & 0.4 \\
\hline
\end{tabular}

Table (2):Reproductive profile of the study sample $(\mathrm{n}=250)$

\begin{tabular}{|c|c|c|}
\hline Menstrual profile & No & $\%$ \\
\hline \multicolumn{3}{|l|}{ Age of menarche(year) } \\
\hline 11 & 18 & 7.2 \\
\hline 12 & 61 & 24.4 \\
\hline 13 & 69 & 27.6 \\
\hline 14 & 69 & 27.6 \\
\hline 15 & 33 & 13.2 \\
\hline Mean + SD & \multicolumn{2}{|c|}{$13.15 \pm 1.148$} \\
\hline \multicolumn{3}{|l|}{ Menstrual regularity } \\
\hline Regular & 168 & 67.2 \\
\hline Irregular & 82 & 32.8 \\
\hline \multicolumn{3}{|l|}{ Menstrual cycle interval (days) } \\
\hline 24 & 47 & 18.8 \\
\hline $25-29$ & 132 & 52.8 \\
\hline 30 to 34 & 50 & 20 \\
\hline More than 35 days & 21 & 8.4 \\
\hline \multicolumn{3}{|l|}{ Duration of menstrual flow (days) } \\
\hline $2-3$ & 46 & 18.4 \\
\hline $4-6$ & 183 & 73.2 \\
\hline $7-10$ & 21 & 8.4 \\
\hline \multicolumn{3}{|l|}{ No. of pads changed / day } \\
\hline$<2$ pads/ day & 29 & 11.6 \\
\hline $2-4$ pads/ day & 197 & 78.8 \\
\hline$\geq 4$ pads/ day & 24 & 9.6 \\
\hline \multicolumn{3}{|l|}{ Dysmenorrhea } \\
\hline Absent (0) & 8 & 3.2 \\
\hline Mild pain $(<3)$ & 45 & 18 \\
\hline Moderate pain (3-6) & 76 & 30.4 \\
\hline Sever pain $(7-10)$ & 121 & 48.4 \\
\hline \multicolumn{3}{|l|}{ Severity of pre-menstrual syndrome } \\
\hline Mild & 54 & 21.6 \\
\hline Moderate & 81 & 32.4 \\
\hline Severe & 115 & 46 \\
\hline \multicolumn{3}{|l|}{ Family history of Premenstrual syndrome } \\
\hline Yes & 137 & 54.8 \\
\hline \multicolumn{3}{|l|}{ Who's } \\
\hline Mother & 52 & 38 \\
\hline Sister & 65 & 47.4 \\
\hline Aunt & 20 & 14.6 \\
\hline \multicolumn{3}{|l|}{ Impact on daily activity } \\
\hline No effect & 26 & 10.4 \\
\hline Effect & 224 & 89.6 \\
\hline \multicolumn{3}{|l|}{ How: } \\
\hline Not going out with the family out of the house & 122 & 54.5 \\
\hline Relying on others to care for self & 100 & 44.6 \\
\hline Not Attend Classes & 66 & 29.5 \\
\hline Not Attend the clinical training & 22 & 9.8 \\
\hline Low test score average & 16 & 7.1 \\
\hline
\end{tabular}


Reproductive and demographic Predictors' of premenstrual syndrome severity among university

Table (3):Premenstrual symptomatology in cycle $1 \&$ cycle 2 as perceived by the study sample

\begin{tabular}{|c|c|c|c|c|}
\hline \multirow{2}{*}{ Premenstrual Symptomatology } & \multicolumn{2}{|c|}{ cycle 1} & \multicolumn{2}{|c|}{ cycle 2} \\
\hline & NO & $\%$ & NO & $\%$ \\
\hline \multicolumn{5}{|l|}{ Physical symptoms } \\
\hline$\leq 3$ & 26 & 10.4 & 24 & 9.6 \\
\hline $4-6$ & 61 & 24.4 & 59 & 23.6 \\
\hline$\geq 7$ & 163 & 65.2 & 167 & 66.8 \\
\hline \multicolumn{5}{|l|}{ Psychological symptoms } \\
\hline$\leq 2$ & 34 & 13.6 & 35 & 14 \\
\hline $3-4$ & 60 & 24 & 58 & 23.2 \\
\hline$\geq 5$ & 156 & 62.4 & 157 & 62.8 \\
\hline \multicolumn{5}{|l|}{ Behavioral symptoms } \\
\hline$\leq 2$ & 44 & 17.6 & 47 & 18.4 \\
\hline $3-4$ & 61 & 24.4 & 58 & 23.2 \\
\hline$\geq 4$ & 145 & 58 & 146 & 58.4 \\
\hline
\end{tabular}

Figure 1: Percentage of premenstrual physical symptoms Cycle 1and cycle 2

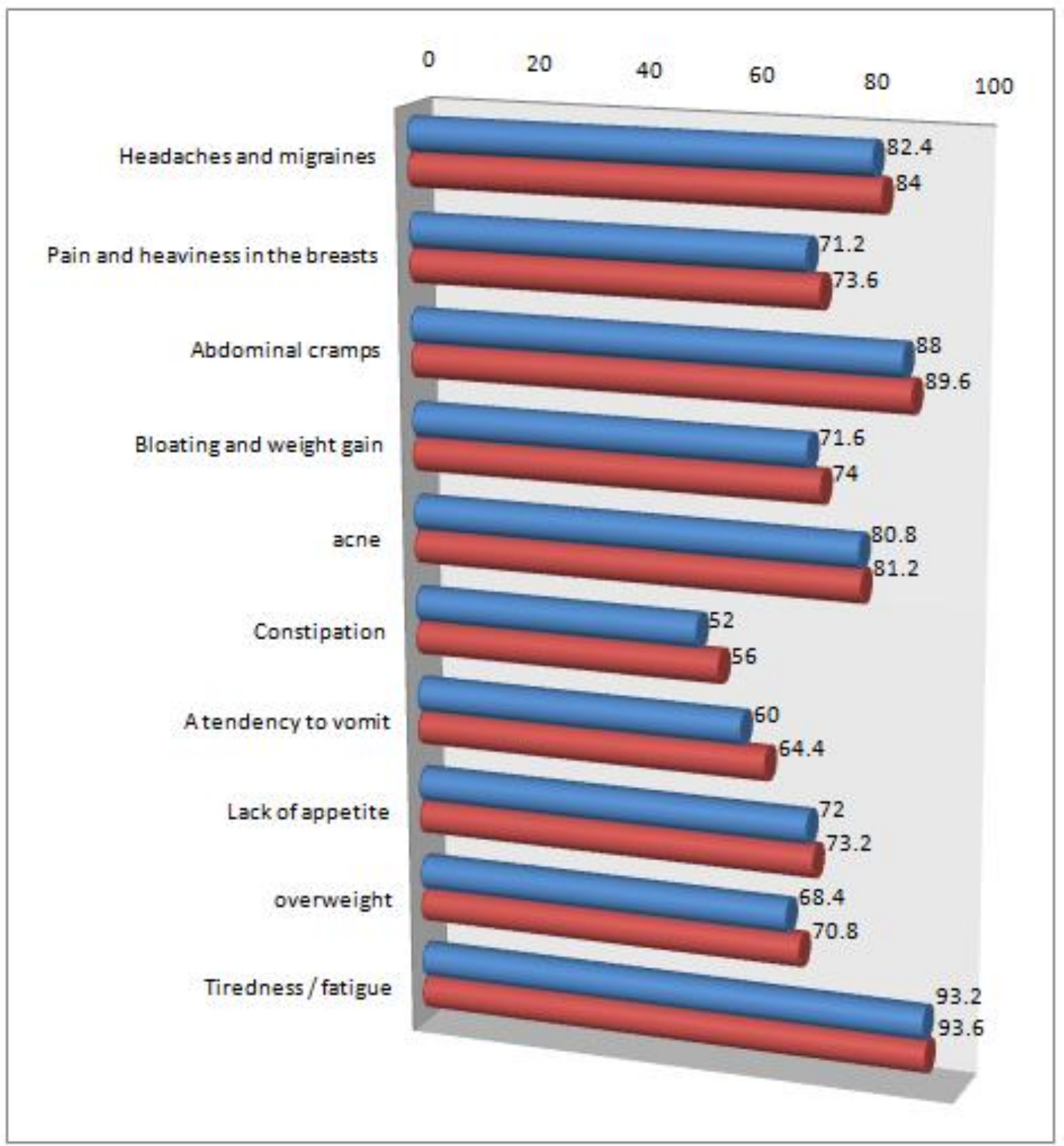


Figure 2: Percentage of premenstrual psychological symptoms in cycle 1and cycle 2

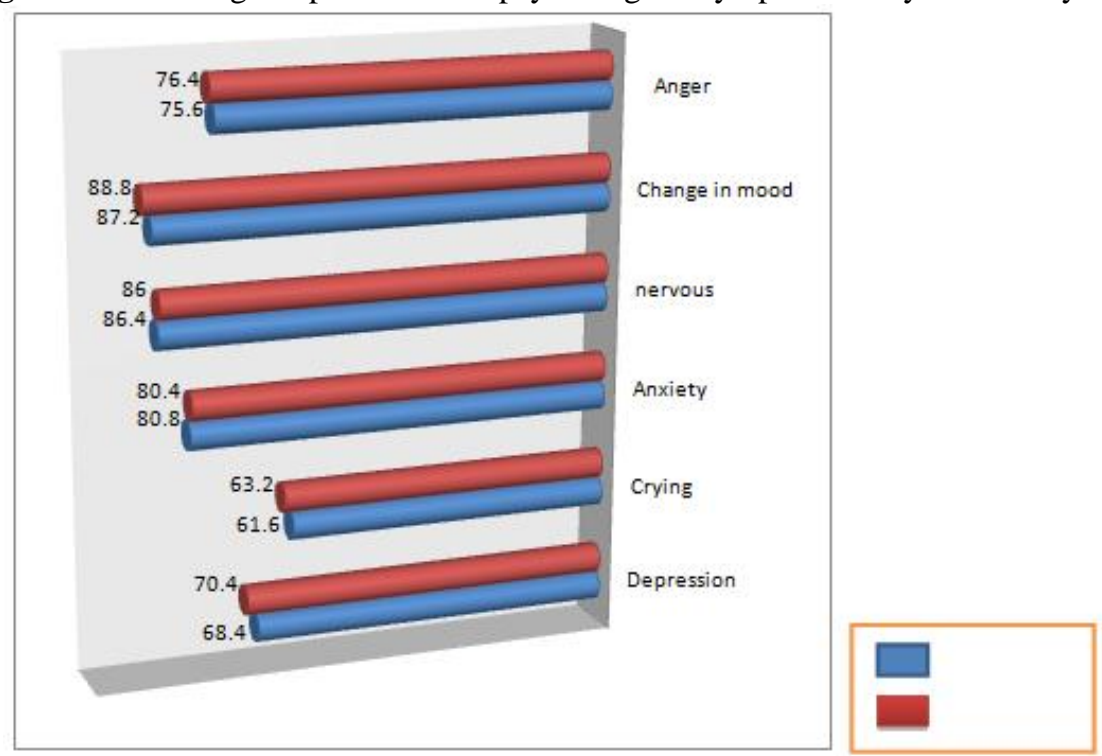

Figure 3: Percentage of Premenstrual behavioral symptoms in cycle 1and cycle 2

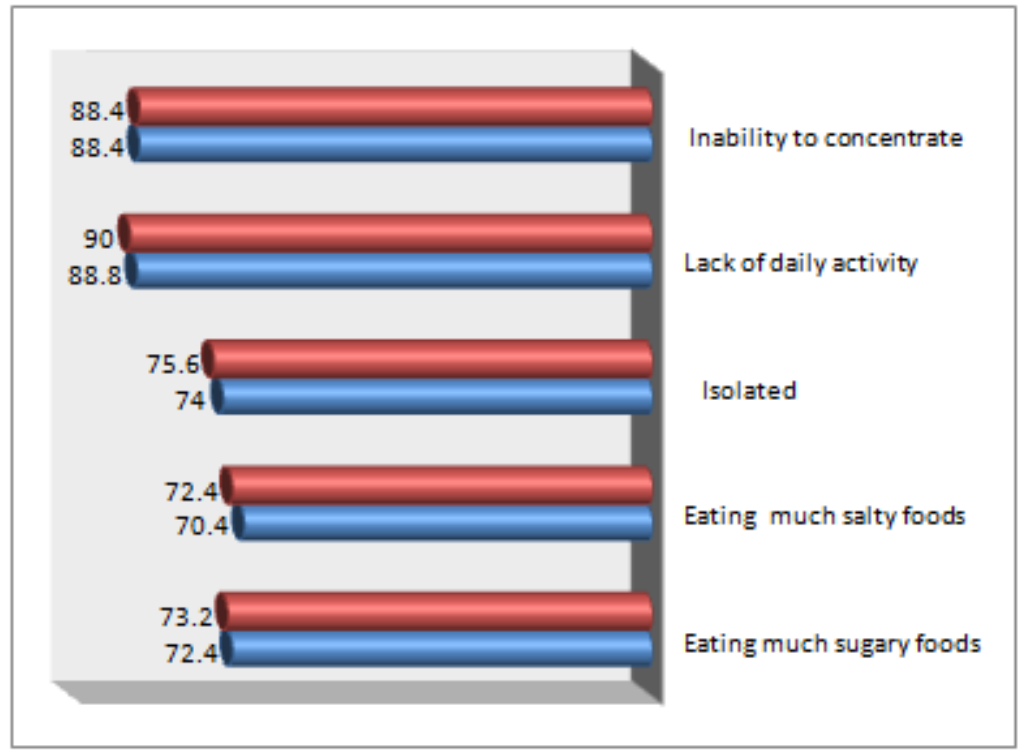

Table4: Relationship between demographic predictors and Premenstrual Syndromes Severity

\begin{tabular}{|l|l|l|l|l|l|}
\hline & \multicolumn{3}{|l|}{ Premenstrual syndrome severity } & Chi-Square & P value \\
\hline Variable & Mild & Moderate & Severe & & \\
\hline Age & (No.)\% & (No.)\% & (No.)\% & & \\
\hline $18-20$ & & & & & \\
\hline $21-23$ & $(38) 22.9$ & $(44) 26.5$ & $(84) 50.6$ & & \\
\hline $24-26$ & $(14) 18.4$ & $(29) 38.2$ & $(33) 43.4$ & 3.515 & 0.476 \\
\hline College Type & $(2) 25$ & $(2) 25$ & $(4) 50$ & & \\
\hline Theoretical & & & & & \\
\hline Practical & $(16) 13.7$ & $(29) 24.8$ & $(72) 61.5$ & 16.231 & \multirow{2}{*}{} \\
\hline The number of family members & $(38) 28.6$ & $(46) 34.6$ & $(49) 36.8$ & & \\
\hline $4-6$ & $(40) 19$ & $(66) 31.2$ & $(105) 49.8$ & 11.779 & 0.019 \\
\hline $7-9$ & $(14) 37.8$ & $(7) 18.9$ & $(16) 43.3$ & & \\
\hline $10-11$ & $(0) 0.0$ & $(2) 100$ & $(0) 0.0$ & & \\
\hline Academic year & & & & & \\
\hline First & $(20) 25.6$ & $(21) 26.9$ & $(37) 47.5$ & & \\
\hline
\end{tabular}


Reproductive and demographic Predictors' of premenstrual syndrome severity among university

\begin{tabular}{|c|c|c|c|c|c|}
\hline Second & (5)12.5 & (7) 17.5 & $(28) 70$ & \multirow{3}{*}{12.116} & \multirow{3}{*}{0.059} \\
\hline Third & (24)24.5 & (34)34.7 & $(40) 40.8$ & & \\
\hline Fourth & (5)14.7 & (13)38.2 & (16)47.1 & & \\
\hline \multicolumn{6}{|l|}{ Residence } \\
\hline Rural & (37) 23.3 & (43) 27 & (79) 49.7 & 1.986 & 0.371 \\
\hline Urban & (17) 18.6 & (32) 35.2 & (42) 46.2 & & \\
\hline \multicolumn{6}{|l|}{ Mother's level of education } \\
\hline Not read or write & (7)25 & (11)39.3 & (10)35.7 & \multirow{7}{*}{23.02} & \multirow{7}{*}{0.02} \\
\hline Read and write & (2) 9.5 & (4)19.1 & $(15) 71.4$ & & \\
\hline Primary & (4)57.1 & (1) 14.3 & (2)28.6 & & \\
\hline Preparatory & (6)40 & (1) 6.7 & $(8) 53.3$ & & \\
\hline Secondary & $(26) 25$ & (32)30.8 & $(46) 44.2$ & & \\
\hline University & (8) 11.6 & (23)33.3 & (38)55.1 & & \\
\hline Post graduate & (1) 16.7 & (3)50 & (2)33.3 & & \\
\hline \multicolumn{6}{|l|}{ Body mass index } \\
\hline Under weight $\left(16-18.5 \mathrm{Kg} / \mathrm{m}^{2}\right)$ & (1) 25 & (1) 25 & (2) 50 & \multirow{5}{*}{12.065} & \multirow{5}{*}{0.148} \\
\hline Normal weight $\left(18.5\right.$ to $\left.25 \mathrm{Kg} / \mathrm{m}^{2}\right)$ & (35) 25.4 & $\begin{array}{ll}(48) & 34.8 \\
\end{array}$ & $\begin{array}{ll}(55) & 39.8 \\
\end{array}$ & & \\
\hline Over weight $\left(25\right.$ to $\left.30 \mathrm{Kg} / \mathrm{m}^{2}\right)$ & (16) 16.8 & (21) 22.1 & (58) 61.1 & & \\
\hline Mild obesity (30 to $35 \mathrm{Kg} / \mathrm{m}^{2}$ ) & (2) 16.6 & (5) 41.7 & (5) 41.7 & & \\
\hline Moderate obesity (35 to $40 \mathrm{Kg} / \mathrm{m}^{2}$ ) & (0) 0.0 & (0) 0.0 & (1) 100 & & \\
\hline
\end{tabular}

Table5: Relationship between Reproductivepredictors and Premenstrual Syndromes Severity

\begin{tabular}{|c|c|c|c|c|c|}
\hline \multirow[b]{2}{*}{ Variable } & \multicolumn{3}{|c|}{ Premenstrual syndrome severity } & \multirow{2}{*}{$\begin{array}{l}\text { Chi- } \\
\text { Square }\end{array}$} & \multirow[t]{2}{*}{ P value } \\
\hline & Mild & Moderate & Severe & & \\
\hline & No.\% & No.\% & No.\% & & \\
\hline \multicolumn{6}{|l|}{ Menstrual regularity } \\
\hline Regular & $(40) 23.8 \%$ & $(55) 32.7 \%$ & $(73) 43.5 \%$ & \multirow[t]{2}{*}{5.028} & \multirow[t]{2}{*}{0.081} \\
\hline Irregular & $(14) 17.1 \%$ & $(20) 24.4 \%$ & $(48) 58.5 \%$ & & \\
\hline \multicolumn{6}{|c|}{ Menstrual cycle interval(days) } \\
\hline 24 & $(5) 10.6 \%$ & (6) $12.8 \%$ & $(36) 76.6 \%$ & \multirow{4}{*}{24.893} & \multirow{4}{*}{$<0.05$} \\
\hline $25-29$ & (37)28\% & $(47) 35.6 \%$ & $(48) 36.4 \%$ & & \\
\hline $30-34$ & $(8) 16 \%$ & (14)28\% & $(28) 56 \%$ & & \\
\hline More than 35 days & (4)19\% & (8) $38.1 \%$ & (9) $42.9 \%$ & & \\
\hline \multicolumn{6}{|c|}{ No. of pads changed / day } \\
\hline $1-2$ pads/ day & $(10) 34.5 \%$ & (6) $20.7 \%$ & (13)44.8\% & \multirow{3}{*}{4.069} & \multirow{3}{*}{0.397} \\
\hline 2-4 pads/ day & (39) $19.8 \%$ & $(63) 32 \%$ & $(95) 48.2 \%$ & & \\
\hline$\geq 4$ pads/ day & $(5) 20.8 \%$ & $(6) 25 \%$ & $(13) 54.2 \%$ & & \\
\hline \multicolumn{6}{|c|}{ Duration of menstrual flow(days) } \\
\hline $2-3$ & (11) $23.9 \%$ & $(14) 30.4 \%$ & $(21) 45.7 \%$ & \multirow{3}{*}{3.685} & \multirow{3}{*}{0.450} \\
\hline $4-6$ & (39) $21.3 \%$ & (58)31.7\% & $(86) 47 \%$ & & \\
\hline $7-10$ & (4) $19 \%$ & (3) $14.3 \%$ & $(14) 66.7 \%$ & & \\
\hline \multicolumn{6}{|l|}{ Dysmenorrhea } \\
\hline Mild pain $(<3)$ & (41)91.1\% & $(4) 8.9 \%$ & $(0) 0.00 \%$ & \multirow{3}{*}{413.422} & \multirow{3}{*}{$<0.05$} \\
\hline Moderate pain (3-6) & $(5) 6.6 \%$ & (71)93.4\% & $(0) 0.00$ & & \\
\hline Sever pain (7-10) & $(0) 0.00 \%$ & $(0) 0.00 \%$ & (121)100\% & & \\
\hline \multicolumn{6}{|c|}{$\begin{array}{l}\text { Family history of Premenstrual } \\
\text { syndrome }\end{array}$} \\
\hline Yes & (18)13.1 & (32)23.4 & (87) 63.5 & 28.790 & $<0.05$ \\
\hline No & (36)31.8 & (43)38.1 & (34) 30.1 & & \\
\hline
\end{tabular}

\section{Discussion}

Findings of this research indicated that younger age was associated with severe PMS compared to older one. This finding is matched with study by Thu andDiaz, (14) that older age is associated with less PMS severity $(\mathrm{p}=0.02)$. Also,Amjad,(15)found significant relationship between age and severity ofPMS $(\mathrm{P}=$ $<0.001)$.On the contrary,Naeimi,(16).reported that there was no significant relationship between age and severity of PMS (P value $=0.593$ ). Also, results of the current study found that students' studies in theoretical college had sever PMS compared to practical college. This finding not supported byNisar,(8) findings that $59.5 \%$ of medical students in Pakistan had mild PMS,29.2\% had moderate and $11.2 \%$ has sever PMS. The variability of PMS severity in the literature might be due to the fact that these studies were conducted with different age groups and population with different sociocultural background.

Regarding to theResidence; the study findings not detected any significant predictors for PMS severity. This finding not supported by study conducted by Amjad, (15) who found significant differences between residence and severity of PMS $(\mathrm{p}=<0.001)$ as $85.62 \%$ of Urbanparticipants suffer from sever PMS. The discrepancy in prevalence estimate may be due to various factors including differences in the study tool, methodology, study area, and characteristics of study participants. Also, results in this study found a significant relation between type of college and occurrence of PMS. This finding not in agreement with IŞIK,(17) who 
found no significant relationbetween type of college and PMS. Also,Nisar,(8)reported that $59.5 \%$ of medical students in Pakistan had mild PMS, 29.2\% had moderate and 11.2\% has sever PMS. The variability of PMS severity in the literature might be due to the fact that these studies were conducted with different age groups and population with different sample size and sociocultural background.In addition,no significant differences were found between level of academic year and severity of PMS. This findings supported by study of Tolossa,(5) .

For Mother's level of Education.In this study findings, a significant relation between Mother's level of education $(\mathrm{p}=0.028)$ and the occurrence of PMS was detected. This result was consistent with studies in different countries indicated that PM symptoms are more common among high-level educated women than noneducated women with a possible association of stress with PMS $(18,19)$.This findings bot supported by Study by IŞIK,(17) who investigate the incidence of PMS, risk factors affecting PMS symptoms, and life quality in health science students, the study findings found no significant relationship between mother's education level $(\mathrm{p}=0.417)$ and severity of PMS. This controversy might be sample size, cultural and socioeconomic differences. Un fortunately, the findings of this study don't support that BMI to be a predictors variable that might affect PMS as more than half from the study sample $(61.1 \%)$ reported severe PMS.This results are not supported by Seedhom,(20)who reported that obese women were more likely to have sever PMS thanamong normal weight.Also, Study conducted by Bertone,(21)found that BMI was also positively associated with risk of specific physical and emotional symptoms, including swelling of the extremities, backache, abdominal cramping, diarrhea/constipation, mood swings, and food cravings. This disagreement between our results and other studies might be due to differences in BMI categories, sample size differences, differences in subjects age and educational activity as well as, practicing exercises or not.

\section{Reproductive predictors}

Regarding to Menstrual regularity,the result illustrated that more than two thirds (67.2\%) percent of the sample had regular menstruation with no significant relation between menstrual regularity and severity of PMS; This findings in agreement with study byGamal,(22)that more than half of Egyptian (Menoufia) and Hodidha clients had regular menstrual cycle with no significant relation between menstrual regularity and severity of PMS ( $\mathrm{p}=0.120)$.This findings not supported by ISSIK,(17) who reported that women experience irregular menstruation are more likely to suffer from severe PMS.

For the duration menstrual flow, the study findings reveal that $73.2 \%$ of study samples had menstrual duration ranged from 2-6 days, with no any significant differences was found between durationof menstrualflow and severity of PMS. This findings in agreement with study by Gamal,(22)who found thatno statistically ( $\mathrm{p}=$ 0.48 ). On the contrary, Tolossa,(5) who found significant relationship between duration of flow and severity of PMS ( $\mathrm{p}=0.024)$. This controversy might be due to differences in age categories of the study sample, marital status, using contraceptive methods or not as well as health condition of the study participant.Concerning the amount of menstrual blood loss, the majority of participants were change 2to 4 pads / day (moderate) menstrual bleeding with no significant relationship between amount of menstrual blood loss and severity of PMS. This finding Similar with study by Soo-Ho,(23)who found no significant between amount of menstrual blood loss and severity of PMS ( $p=0.413)$.Regarding to menstrual interval,the study finding found a significant relationship between menstrualinterval and severity of PMS. This finding not supported by Nageebfinding,(24)who found no significant relationship between menstrualinterval and severity of PMS ( $\mathrm{p}=$ 0.242).This controversy might be other factors such as environment, food habits or obstetrical disease. Regarding to dysmenorrhea, the current study found more than half of the study sample $(n=121)$ had severdysmenorrhea, which was significantly related with severe premenstrual symptoms and higher scores on visual analogue scale.These findings agree with study by Steiner,(25)who reported that the prevalence of dysmenorrhea was high, particularly in those with severe PMS or PMDDas $63.7 \%$ from the study sample suffer from no/mild PMS, $81.7 \%$ experience severe PMS.Although some studies have reported no relation between dysmenorrhea and PMS $(17,26)$. The rational for this finding due to the Biochemical changes in severe PMS and dysmenorrhea may correspond with each other, and reduced prostaglandin levels may relieve both of them. Moreover, the treatment of dysmenorrhea may help to reduce premenstrual symptoms and related difficulties in school regarding to dysmenorrhea and performance among young women.Also, a significant relationship was found between family history and severity of PMS within family members. This findings supported by Oral, (26),ISIK, (17) and Seedhom, (20).theyobserved that PMS mother/daughter dyads experienced significantly more and severe luteal phase symptoms compared to non-PMS mother/daughter dyads.

\section{Conclusion and Recommendations}

Based on the findings of the present study, it can be concluded that, type of collage, mothers' levels of education, family history of PMS, menstrual cycle intervals were the important predictors that might affect severity of PMS. Also, the results indicated that, menstrual irregularities, BMI and duration of menstrual flow were not statistically significant in relation to severity of PMS. 
Based on the study findings, the following are recommended:

- Raise student's awareness regarding premenstrual syndrome and ways to adopting healthy life style as follow dietary program and practice exercise

- Secondary school curricula should contain items related to associated symptoms related to menstrual cycle and ways to handlethis symptom.

*Further studies are recommended regarding to the following issues:

- The relation between PMS and lifestyle habits such as amount of caffeine consumption and sleep habits.

- Live experience of PMSamong adolescent females

\section{Acknowledgements:}

Researchers would like to thank all students who participated in this study.

\section{References}

[1]. Nulufer E, Ayşenur K, Tulay K.(2010).Investigation of premenstrual syndrome and contributing factors among university students. Turk J Med Sci, 40(4):565-573.

[2]. Myint T, Edessa Ore-Giron D, Sawhsarka P.(2006). Premenstrual Syndrome among Female University Students in Thailand. Assumption Univ J Technol, 9(3):158-162.

[3]. Adiguzel H, Taskin EO, DanaciAE(2007). The symptomatology and prevalence of symptoms of premenstrual syndrome in Manisa, Turkey.Turk PsikiyatriDergisi.18 : 215-222.

[4]. Goker A, Artunc-Ulkumen B, Aktenk F, Ikiz N.(2014). Premenstrual syndrome in Turkish medical students and their quality of life.J ObstetGynaecol. ; $20: 1-4$.

[5]. Tolossa F., Wakjira\&Bekele M., Legesse .(2014) "Prevalence, impacts and medical managements of premenstrual syndrome among female students: cross-sectional study in college of health sciences, Mekelle University, Mekelle, Northern Ethiopia" BMC Women's Health, 14:52 http://www.biomedcentral.com/1472-6874/14/52.

[6]. Dickerson LM, Mazyck PJ, Hunter MH. (2003).Premenstrual syndrome. Am Fam Physician;67(8):1743e52.

[7]. Halbriech U, Borenstien J, Pearlstein T, Kahn LS.(2003). The prevalence, impairment, impact and burden of premenstrual syndrome dysphoric disorder. Psychoneuroendocrinology;3:1e23.

[8]. Nisar N, Zehra N, Haider G, Munir AA, Sohoo NA.(2008). Frequency, intensity and impact of premenstrual syndrome in medical students. J Coll Physicians Surg Pak;18(8):481e4.

[9]. Nillini YI, Rohan KJ, Mahon JN, Pineles SL, Zvolensky MJ.(2013). The role of anxiety sensitivity in the experience of menstrualrelated symptoms reported via daily diary. Psychiatry Res;210:564e9.

[10]. Bianco V, Cestari AM, Casati D, Cipriani S, Radici G, Valente I. (2014).Premenstrual syndrome and beyond: lifestyle, nutrition and personal facts. Minerva Ginecol;66(4):365e75.

[11]. Cheng SH, Shih CC, Yang YK, Chen KT, Chang YH, Yang YC. (2013). Factors associated with premenstrual syndrome- A survey of new female university students. Kaohsiung J Med Sci;29:100e5.

[12]. Sahin S, Ozdemir K, Unsal A. Evaluation of premenstrual syndrome and quality of life in university students. J Pak Med Assoc 2014;64(8):915e22.

[13]. Eke, A. C., Akabuike, J. C., \&Maduekwe, K. (2011). Predictors of premenstrual syndrome among Nigerian university students.International Journal of Gynaecology and Obstetrics, 112(1), 63.

[14]. Thu, M., Diaz, E.O.G. and Sawhsarkapaw. (2006). Premenstrual Syndrome among Female University Students inThailand. AU Journal of Technology, 9, 158-162.

[15]. Amjad A., Kumar R and Mazher S.B.(2014)" Socio-demographic Factors and Premenstrual Syndrome among Women attending a Teaching Hospital in Islamabad, Pakistan" J PIONEER MED SCI. Volume 4, Issue 4. October-December, 2014 p $159-162$ .www.jpmsonline.com.

[16]. Naeimi, N. (2015). The Prevalence and Symptoms of Premenstrual Syndrome under Examination. Journal of Biosciences and Medicines, 3, 1-8. http://dx.doi.org/10.4236/jbm.2015.31001.

[17]. Isik, H.,Ergol,S.,Aynioglu,O., Sahbaz,A., Kuzu, A., and Uzum,M.(2016) . Premenstrual syndrome and life quality in Turkish health science students. Turk J Med Sci ,46: 695-701c TUBITAK doi:10.3906/sag-1504-140, http://journals.tubitak.gov.tr/medical/.

[18]. Pinar, G., Colak, M., Oksuz, E.(2011). Premenstrual syndrome in turkish college students and its effects on life quality", SexReprod Health; 2:21-27.

[19]. Schiola, A., Lowin, J., Lindemann, M., Patel, R., Endicott, J. (2011). The burden of moderate/severe premenstrual syndrome and premenstrual dysphoric disorder in a cohort of Latin American women.Value Health; 14:S93-S95.

[20]. Seedhom . A, Mohammed. E and Mahfouz. E .(2013). Life style factors associated with premenstrual syndrome among El-Minia University students, Egypt. ISRN Public Health Volume 2013, Article ID 617123, 1-6. http://dx.doi.org/10.1155/2013/617123.

[21]. E. R. Bertone-Johnson, S. E. Hankinson, W. C. Willett, et al.(2010). Adiposity and the development of premenstrual syndrome. Journal of Women's Health, vol. 19, no. 11, pp. 1955-1962, 2010. View at Publisher • View at Google Scholar

[22]. Gamal,A.M. \&Shahin,M.A. (2015). Premenstrual Syndrome, Associated Symptoms and Evidence - Based Nursing Management: A Comparative Study BetweenRuralMenoufia Governorate (Egypt) and HodidhaGovernorate (Yemen). American Journal of Nursing Science. Vol. 4, No. 3, pp. 84-93. doi:10.11648/j.ajns.20150403.16.

[23]. Soo-Ho Chung, Tae-Hee Kim, Hae-Hyeog Lee, Arum Lee1, Dong-Su Jeon, Junsik Park, Yesol Kim. (2014).Premenstrual Syndrome and Premenstrual Dysphoric Disorder in Perimenopausal Women. Journal of Menopausal Medicine; 20: 69-74.

[24]. Nageeb H. , Mohamed R.A. and Amasha H.(2015). Prevalence of Premenstrual Syndrome: Complementary \& Alternative Therapy among Nursing Students. IOSR Journal of Nursing and Health Science (IOSR-JNHS) e-ISSN: 2320-1959.p- ISSN: 23201940 Volume 4, Issue 2 Ver. IV (Mar.-Apr. 2015), PP 07-15 www.iosrjournals.org DOI: 10.9790/1959-04240715 www.iosrjournals.org 7 | Page

[25]. Steiner M, Peer M, Palova E, Freeman EW, Macdougall M, Soares CN.(2011). The Premenstrual Symptoms Screening Tool revised for Adolescents (PSST-A): Prevalence of severe PMS and premenstrual dysphoric disorder in adolescents. Arch Women's Ment Health. ;14:77-81.

[26]. E. Oral, T. S. Kirkan, E. Yazici, M. Gulec, Z. Cansever, N. Aydin. (2012). Premenstrual Symptom Severity, Dysmenorrhea, and School Performance in Medical Students. Journal of Mood Disorders Volume: 2, Number: 4, 2012 - www.jmood.org. 